\title{
Is the lag screw sliding effective in the intramedullary nailing in A1 and A2 AO-OTA intertrochanteric fractures? A prospective study of Sliding and None-sliding lag screw in Gamma-III nail
}

Yi Zhu', Severin Meili², Changqing Zhang ${ }^{1 *}$, Congfeng Luo ${ }^{1}$ and Bing-fang Zeng ${ }^{1}$

\begin{abstract}
Object: To compare the Sliding with Non-sliding lag screw of a gamma nail in the treatment of A1 and A2 AO-OTA intertrochanteric fractures.

Materials and methods: 80 patients were prospectively collected. In each group, AO/OTA 31-A were classified into group A. AO/OTA 31-A2.1 was classified as group B. We classified the A2.2 and A2.3 as group C. According to the set-screw locking formation of Gamma-III, the cases were randomly allocated to Sliding subgroup and Non-sliding subgroup in A, B and C groups. Follow-ups were performed 1, 3, 6 and 12 months postoperatively.

Results: In the Sliding group, the bone healing rate 3, 6, 12 months postoperatively reached $85.00 \%, 97.50 \%$, $100 \%$ in group A, B and C. Meanwhile, in Non-sliding group, postoperatively, bone healing rate were $90.00 \%$, $95.00 \%$ and $97.50 \%$ in group A, B and C, respectively. Both differences were not significant. Lower limb discrepancy between Sliding and Non-sliding pattern was significantly different in group $C$ which represent fracture types of AO/OTA 31-A2.2 and A2.3 $(0.573 \pm 0.019 \mathrm{~mm}$ in Non-sliding group, $0.955 \mathrm{~mm} \pm 0.024 \mathrm{~mm}$ in Sliding group, $\mathrm{P}<$ 0.001 ). Difference of sliding distance among the three groups was significant among group $A, B$ and $C: 0.48 \mathrm{~mm} \pm$ $0.04 \mathrm{~mm}, 0.62 \mathrm{~mm} \pm 0.07 \mathrm{~mm}$ and $0.92 \mathrm{~mm} \pm 0.04 \mathrm{~mm}$ ( $P<0.001$ ). Differences in average healing time and Harris scores also presented no significance in the three groups.

Conclusions: As a result, we can conclude that the sliding distance is minimal in Gamma nails and it is related to the comminuted extent of the intertrochanteric area in A1 and A2 AO-OTA intertrochanteric fractures. For treating these kinds of fractures, the sliding of the lag screw of an Gamma nail does not improve any clinical results and in certain cases, such as highly comminuted A1 and A2 fractures, can therefore even benefit from a locked lag screw by tightening the set-screw.
\end{abstract}

Keywords: Intertrochanteric fractures, A1 and A2 AO-OTA, Gamma nail, Lag screw sliding

\footnotetext{
* Correspondence: zhangcq1964@yahoo.cn

'Department of Orthopaedics, Shanghai Sixth People's Hospital, Shanghai Jiaotong University, No.600, YiShan Road, Xuhui District, Shanghai 200233, China

Full list of author information is available at the end of the article
} 


\section{Introduction}

The Dynamic Hip Screw (DHS) and the Gamma Nail are the most acceptable fixation methods to treat intertrochanteric fractures [1-5]. The best advantage of the DHS is the dynamical lag screw, which can promote the compression of the fracture line [6-8]. This technique has been proved to stimulate the callus formation $[9,10]$ and applied widely such as dynamic compression plate, external fixation and dynamization of intramedullary nailing [11,12].

The Gamma Nail is a stiffer implant and has a shorter lever arm, which makes itself a load-sharing device. Furthermore, biomechanical experiments supported that the sliding ability of the lag screw was maintained in the Gamma Nail, but decreased in comparison with the DHS device $[7,13,14]$. Up to the present, no clinical results support whether the Gamma nail can take advantage of the sliding screw, especially in stable intertrochanteric fractures. Our goal is to compare the healing time, Harris Hip Score, lower limb discrepancy as well as the sliding distance between two groups with a sliding and non-sliding lag screw pattern in the Gamma Nail among 31-A1 and A2 AO-OTA intertrochanteric fractures. In order to avoid the impact of osteoporosis on the device $[2,15]$, only younger healthy patients with better bone quality were enrolled in our study.

\section{Materials and methods}

\section{Patient selection and grouping}

From 2008.1.1 to 2010.12.31, a total of 325 cases suffered from intertrochanteric fractures in the clinical center of orthopedic trauma in Shanghai Sixth People's hospital. The inclusion criteria are: (1) age $>18$ and $<60$ years old, (2) fresh, closed fracture, (3) no combined fracture, (4) AO/OTA 31-A1, A2 with integrate lateral wall. The exclusion criteria are: (1) pathological or open fracture, (2) combined with diseases of the cardiac system, the hematologic system or other systems, (3) osteoporosis (Singh index $\leqq 3$ ). Among these, 80 patients satisfied the criteria and were undergone fixation by Gamma-III nail (Stryker, Schonkirchen, Germany).

All the cases were chosen as $31-\mathrm{A} 1$ and A2 fractures determined by AO/ASIF classification because they are intertrochanteric fractures without the reversed type oblique fracture line. In our study, we classified these cases into group $\mathbf{A}, \mathbf{B}$ and $\mathbf{C}$ for the differences of their comminution (Figure 1). We classified the A2.2 and A2.3 as group $\mathrm{C}$ because they show comminution around the intertrochanteric area and therefore always belong to the unstable patterns $[16,17]$. All the cases were classified simultaneously by 2 observers, a junior-level and fellowship-trained orthopedic traumatologist ( $Y Z$ and SM.) and agreement was reached by consensus. Interobserver reliability measurements were reviewed and
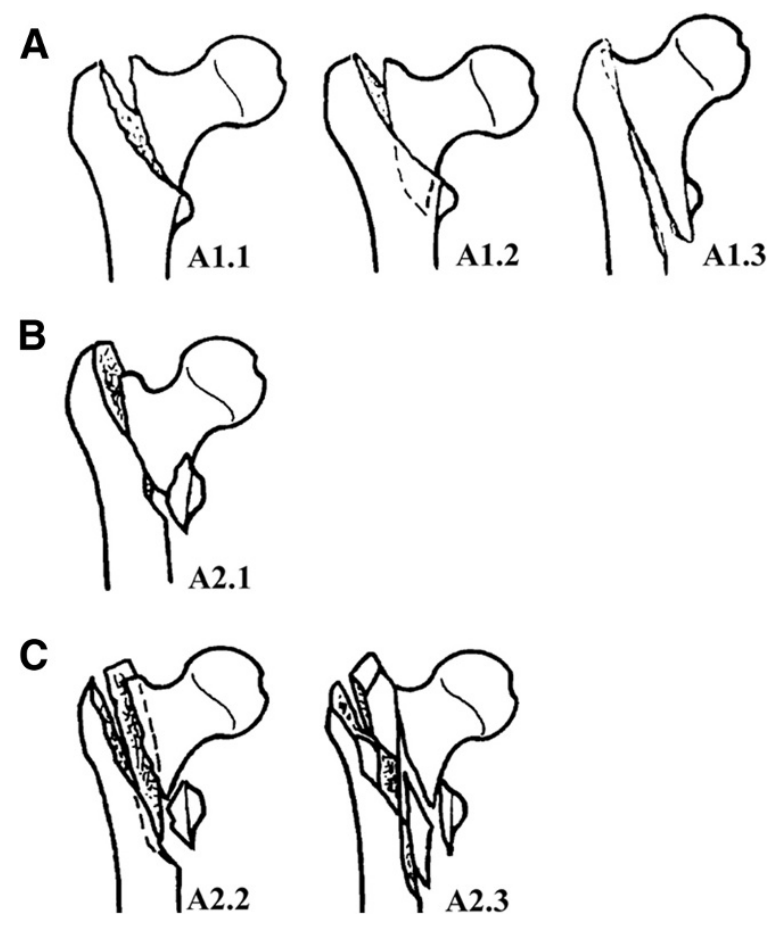

Figure 1 The enrolled fracture types and grouping based on the AO/OTA classification: Group A: AO/OTA 31-A1; Group B: AO/OTA 31-A2.1; Group C: AO/OTA 31-A2.2, 2.3.

reached "substantial agreement". Intra-observer reliability measurements were not performed.

According to the set-screw locking pattern of Gamma Nail [18], the cases were randomly divided into a sliding subgroup and non-sliding subgroup within groups A, $\mathrm{B}$ and $\mathrm{C}$. Sliding or non-sliding is defined by tightening or not tightening the set-screw. Randomization was achieved by drawing an unseen card from a sealed envelope to separate the patients equally into "Sliding group" and "Non-sliding group".

\section{Interventions}

All operations were performed by the same surgeon (CQZ), who had at least 20 years experience in orthopedic trauma. Patients were positioned on the orthopedic traction table and total anesthesia was used. Closed reduction was performed with the aid of $\mathrm{C}$-arm fluoroscopy. Operations were performed adhered to standard protocols for the Gamma-III nail [18]. A Gamma Nail is a $180 \mathrm{~mm}$ Titanium Alloy with Type II proximal anodization with distal diameters of $15.5 \mathrm{~mm}$ and $11 \mathrm{~mm}$. Reaming of the medullary canal was generally performed for all the cases before insertion. The distal locking screw was used. Tightening or not tightening the set-screw in the procedure was according to the randomized card. A sketch map of a lag screw sliding of Gamma is depicted in Figure 2. Drainage tube was 

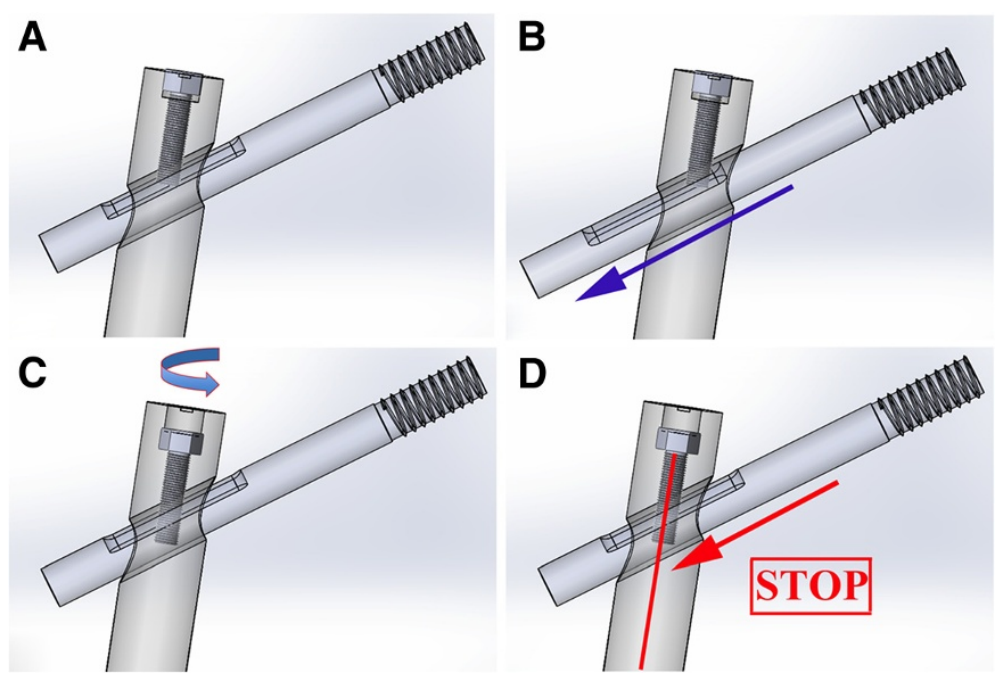

Figure 2 A schematic view of the lag screw sliding in the Gamma Nail. If the set screw was not tightened (as showed in A), after postoperative load bearing, the sliding of the lag screw (blue arrow) will allow fracture site impaction (B). If the set screw is tightened (C) no sliding will occur (D).

placed for each patient for 1 day. None of them needed transfusion postoperatively. Each patient received regular antibiotic prophylaxis for only 1 day postoperatively. Painkillers were not suggested for the patients. The rehabilitation protocol contained two days of bed rest followed by ambulation with immediate weight bearing, eventually allowing the screw sliding and bone impaction. No other physiotherapy was suggested to the patients.

\section{Parameter assessment}

Radiographic observations assessed postoperatively in Xrays were complications, visibility of the fracture line (respectively callus formation) and radiographic bone healing. The bone healing, defined as the presence of bridging callus and the absence of the fracture line, was assessed as radiological union. Clinical judgment was based upon the subjective impression of fracture site pain and fracture stiffness under physical load. Patients were performed a full-leg radiograph 6-months postoperatively and limb length was estimated in PACS system by drawing a line from the top of the femoral head to the center of the tangential line drawn between the most distal part of the medial and lateral femoral condyle as suggested by Platzer et al. [2]. The differences between the distance of the injured and uninjured side were recorded as length of lower limb discrepancy. The measurements of the femoral length of all radiographs were repeated by a second surgeon, to assess the interobserver variability. At the same time, we used a special radiographic method suggested by Lunsjo et al. [19] for calculating the distance of the lag screw sliding.
Follow-ups were performed 1, 3, 6 and 12 months postoperatively. At each postoperative control, radiographs were made and any change in the position of the implant, complication, or fixation failure was recorded. On the 6-months radiograph, the lag screw sliding distance as well as the femoral length discrepancy were calculated between Sliding and non-sliding groups. All measurements were made three times and the means were finally recorded. The Harris hip score was chosen to assess the hip function of the patients 12 months postoperatively in the outpatient clinic. The statistics were measured by YZ and CQZ and were finally recorded before agreement was reached. All the CONSORT guidelines for our study can be read in Figure 3. The study was approved by the Committee of Medical Ethics and the Institutional Review Board of our University.

\section{Statistical analyses}

The Chi square Test was used to analysis the differences between the basic information of the two groups. Significance was set at $\mathrm{p}<0.05$.

To analysis the differences of the Harris hip score, lower limb discrepancy and the healing rate between the Sliding group and Non-sliding group, comparison was performed between the both. A measurement of the sliding distance in the sliding group among groups $\mathrm{A}, \mathrm{B}$ and $\mathrm{C}$ was also performed. The Mann-Whitney $U$ test was used to test for independent groups. Significance was set at $\mathrm{p}<0.05$.

\section{Results}

All the follow-up information is schematically listed in Table 1. The whole information was verified from the 


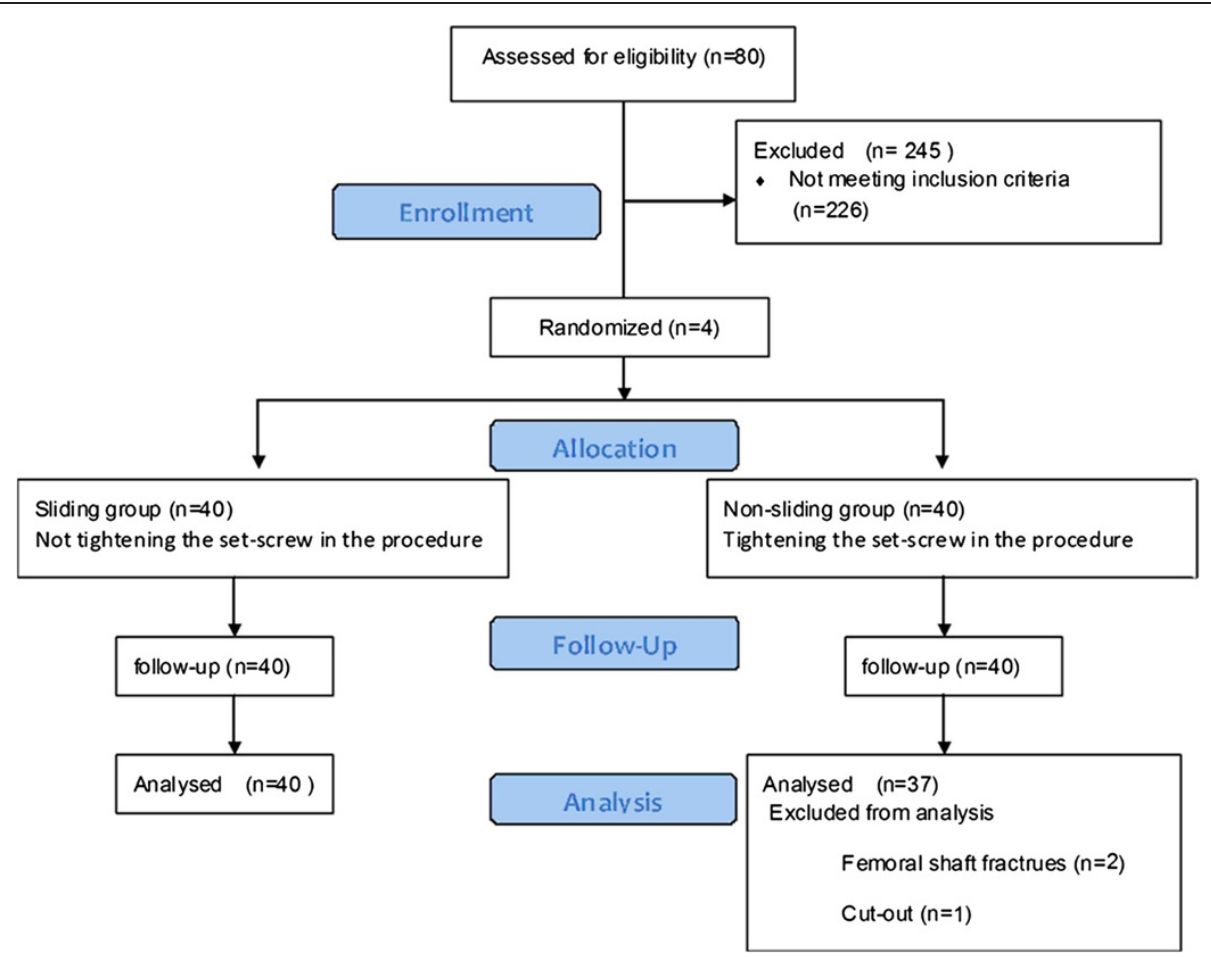

Figure 3 Flow Diagram for our RCT.

charts in the patient history room. Both groups were well matched; all these differences were not significant (NS), especially the average healing time and the Harris hip score in the three groups. The X-rays of a representative case is shown in Figure 4. In one case a cut out phenomenon of the femoral head was observed. Two cases suffered from femoral shaft fractures.

Lower limb discrepancy between Sliding and Nonsliding pattern was significantly different in group $\mathrm{C}$ which represent fracture types of AO/OTA 31-A2.2 and A2.3 $(0.573 \mathrm{~mm} \pm 0.019 \mathrm{~mm}$ in Non-sliding group, $0.955 \mathrm{~mm} \pm 0.024 \mathrm{~mm}$ in Sliding group, $\mathrm{P}<$ 0.001) Figure 5. Difference of sliding distance among the three groups was significant among group A, B and $C: 0.48 \mathrm{~mm} \pm 0.04 \mathrm{~mm}, 0.62 \mathrm{~mm} \pm 0.07 \mathrm{~mm}$ and $0.92 \mathrm{~mm} \pm 0.04 \mathrm{~mm}(\mathrm{P}<0.001)$ Figure 6. Differences in average healing time and Harris scores also presented no significance among group A, B and C.

\section{Discussion}

The similar mechanic characteristic of the Gamma Nail and DHS is the lag screw, which has a mechanical sliding ability of the head-neck fragment relative to the shaft fragment in the intertrochanteric area $[7,8,14,20]$. Adequate purchase of the proximal screw within the femoral head, sufficient stability of the implant and proper sliding of the head-neck fragment provide better stability in the Gamma Nail [14]. It has been mechanically proved that the sliding ability of the lag screw in the Gamma Nail depends on the angle between the screw and the nail as well as the extent of the engaged screw within the barrel of the device [21,22]. Interestingly, there is a small tip in the manipulation of the Gamma Nail [18] which created the idea of our study. As the technique brochure suggests, after slightly tightening the set screw it could then be unscrewed by one quarter of a turn. This ensures a free sliding of the lag screw, which may stimulate the callus formation when early weight bearing is permitted. In contrary, if the set screw is tightened, the sliding is stopped. Therefore, now obtaining a more rigid fixation, we wanted to investigate the clinical benefit from the sliding screw in the Gamma Nail.

According to the AO/ASIF classification, A1 and A2 intertrochanteric fractures, excluding the reversed type fractures as well as a broken lateral wall, there is a good indication for implanting both, the Gamma Nail or the DHS $[17,23]$. Therefore, we aimed to choose these types to investigate the sliding effect in Gamma Nails. To avoid the impact of osteoporosis on the device $[2,15]$, only younger healthy patients were enrolled. In the sliding group, we could show that the difference of the sliding distance 6 months postoperatively is significant among group $\mathrm{A}, \mathrm{B}$ and $\mathrm{C}$, but less than reported in previous studies on the DHS [24]. To the best of our knowledge, a larger bending moment and higher force is required to initiate the sliding in the DHS, due to the 
Table 1 Comparison of patients variables between the Sliding group and Non-sliding group

\begin{tabular}{|c|c|c|c|}
\hline Variables & Sliding group & Non-sliding group & $P$ values \\
\hline Patients(n) & 40 & 40 & \\
\hline Age(y) & $45.55 \pm 9.87$ & $46.83 \pm 8.76$ & 0.453 \\
\hline Gender (Male/Female) & $24 / 16$ & $30 / 10$ & 0.232 \\
\hline Side (Left/Right) & $15 / 25$ & $19 / 21$ & 0.498 \\
\hline Weight 1M postoperatively (kg) & $64.83 \pm 8.79$ & $65.93 \pm 8.68$ & 0.575 \\
\hline \multicolumn{4}{|l|}{ AO classification } \\
\hline Group A (31-A1) & 7 & 4 & \\
\hline Group B (31-A2.1) & 12 & 16 & 0.493 \\
\hline Group C (31-A2.2, A2.3) & 21 & 20 & \\
\hline Operation time (min) & $46.73 \pm 10.37$ & $48.35 \pm 9.23$ & 0.461 \\
\hline Intra-operative blood loss (ml) & $141.1 \pm 18.12$ & $138.5 \pm 19.42$ & 0.538 \\
\hline Tip-Apex Distance (mm) & $22.03 \pm 4.19$ & $21.23 \pm 3.12$ & 0.336 \\
\hline Fracture reduction (mm) & $8.48 \pm 3.34$ & $8.98 \pm 3.50$ & 0.515 \\
\hline Length of hospital stay (days) & $4 \pm 1$ & $4 \pm 1$ & NA \\
\hline Bone healing cases (postoperatively) & 40 & 40 & \\
\hline $3 \mathrm{M}$ & $34(85.00 \%)$ & $36(90.00 \%)$ & \\
\hline $6 \mathrm{M}$ & $39(97.50 \%)$ & 38(95.00\%) & NA \\
\hline $12 \mathrm{M}$ & $40(100 \%)$ & $39(97.50 \%)$ & \\
\hline \multicolumn{4}{|l|}{ Complications } \\
\hline Group A (31-A1) & 0 & 0 & \\
\hline Group B (31-A2.1) & 0 & 2 (Femoral shaft fracture) & NA \\
\hline Group C (31-A2.2, A2.3) & 0 & 1 (Cut-out) & \\
\hline \multicolumn{4}{|l|}{ Average healing time (Months) } \\
\hline Group A (31-A1) & $3.00 \pm 1.13$ & $3.00 \pm 0.00$ & 1 \\
\hline Group B (31-A2.1) & $3.25 \pm 0.87$ & $3.25 \pm 0.87$ & \\
\hline Group C (31-A2.2, A2.3) & $3.23 \pm 0.81$ & $3.85 \pm 3.64$ & \\
\hline \multicolumn{4}{|l|}{ Harris Hip Score } \\
\hline Group A (31-A1) & $88.00 \pm 8.10$ & $90.25 \pm 5.12$ & 0.927 \\
\hline Group B (31-A2.1) & $86.33 \pm 11.85$ & $87.13 \pm 6.60$ & \\
\hline Group C (31-A2.2, A2.3) & $84.52 \pm 5.51$ & $85.60 \pm 10.34$ & \\
\hline
\end{tabular}

longer leverage arm of the implant. Thus, the bending moment is increased in a heavier patient, by a smaller screw-nail angle and by a longer extension of the screw $[7,20,21]$. Maximum engagement of the screw in the barrel and less screw-plate angle would be greater ease of sliding with increasing bone impaction and stability at the fracture site Maximum engagement of the screw in the barrel and less screw-plate angle hinder the sliding with increased bone impaction and stability at the fracture site [22]). All Gamma Nails preferably have a small nail-screw-angle between the nail and the screw because of operative and design-related constraints, which increases the bending moment. The distance over which the screw is engaged in a Gamma nail is shorter than the distance over which it is engaged in a DHS. This fact decreases the ability of the screw to slide through the intramedullary device. Therefore, the sliding properties of commercially available second-generation intramedullary devices would be expected to be lower than those of smaller-angle DHS. That's why the sliding distance in Gamma Nails is fairly short. Furthermore, the rehabilitation protocol consisted of 2 days of bed rest followed by ambulation with immediate weight bearing, eventually allowing the screw sliding and bone impaction. To keep the groups well comparable, both were well matched in fracture type, patients' body weight. Furthermore, our study showed that there is no significance in both groups in the tip-apex-distance (TAD) as well as in the accuracy of fracture reduction. We finally consider that the type of fracture may be one of the reasons, which affects the sliding distance in the Gamma Nail. The more fracture comminution 

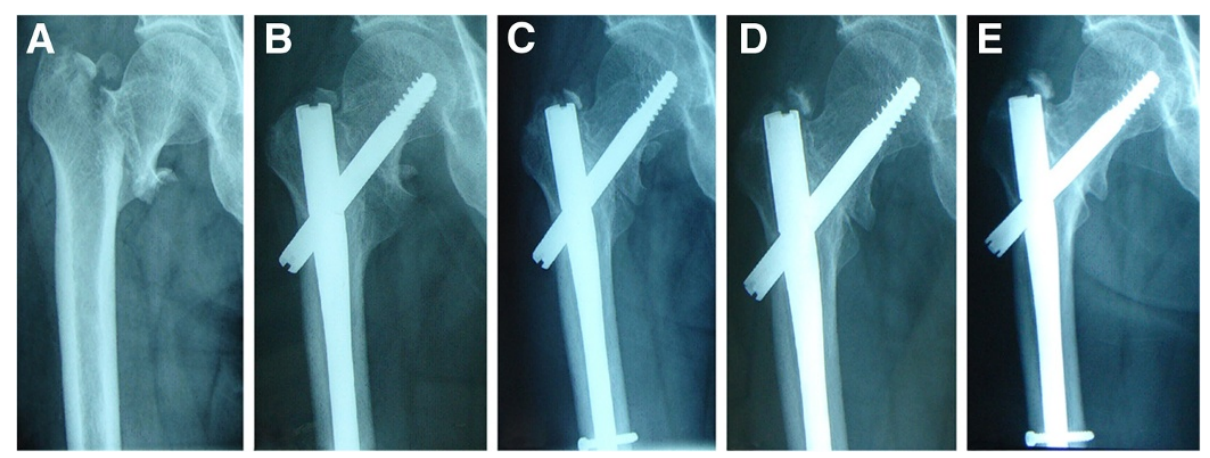

Figure 4 A. 47 years old, male (AO/OTA: 31-A1.2) B.1 month after operation C. 3 months after operation D. 6 months after operation E. 12 months after operation.

around the intertrochanteric area, the more sliding distance can be observed.

One of the well-known complications caused by the sliding of the lag screw is shortening of the leg, which consequently can affect the hip function [6,25]. As proved previously, Osteoporosis, unstable fracture types and early mobilization with immediate weight bearing are also main reasons for lower limb discrepancy $[20,24,26]$. But no comparative study of the Gamma Nail itself, which is mechanically a quite different apparatus in comparison with the DHS in sliding of the lag screw, has been conducted. So far, only one research group focused on the leg shorting using the Gamma nail. Platzer et al. [2] revealed a mean femoral shortening of $10.6 \mathrm{~mm}$ after fixation by Gamma Nail in unstable fracture types (31-A2andA3), while measuring a mean femoral inequality of $5.5 \mathrm{~mm}$ in the stable fracture types (31-A1). In our study, we also utilize the same fixation and grouped the different fracture patterns in order to limit the impact of the comminution for the lag screw sliding or femoral shorting. Therefore, we consider that the results of our research are more convincing in the

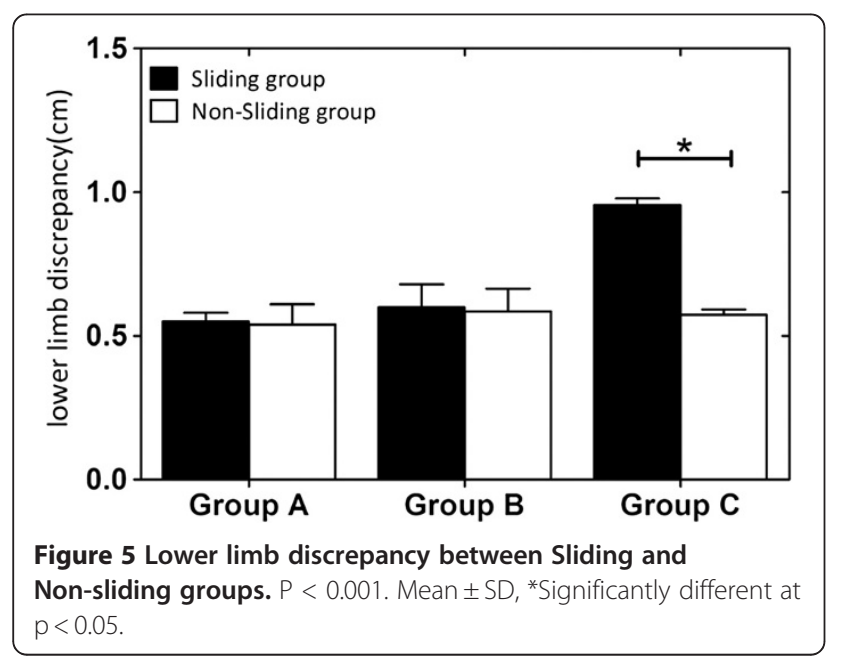

ascertainment of the lag screw influence on Gamma Nail. Finally, we find significant differences in lower limb length inequality in group $\mathrm{C}$ between the sliding and non-sliding lag screw. However, the difference between group A (AO/OTA 31-A1) and group B (AO/OTA 31A2.1) is not significant. Because both groups are well matched, we presume that most likely the reason of lower limb discrepancy is the sliding of the lag screw. The fracture type may be the main reason for the sliding of the lag screw in both groups. Platzer et al. [2] thought that the unstable fracture might cause more shorting. Our data proved that the more comminution in the intertrochanteric area (from group A through C), the more sliding of lag screw, and thus a larger discrepancy lower limb length could be observed in the Gamma Nail.

The bone healing rate in our study is high. Nearly all the cases healed in 12 months postoperatively. Interestingly, the bone healing rate and average healing time shows no relation to the sliding characteristic in our study. The occurred complications were femoral shaft fractures ( 2 cases) and one screw cut-out in the nonsliding group, but healed eventually after additional

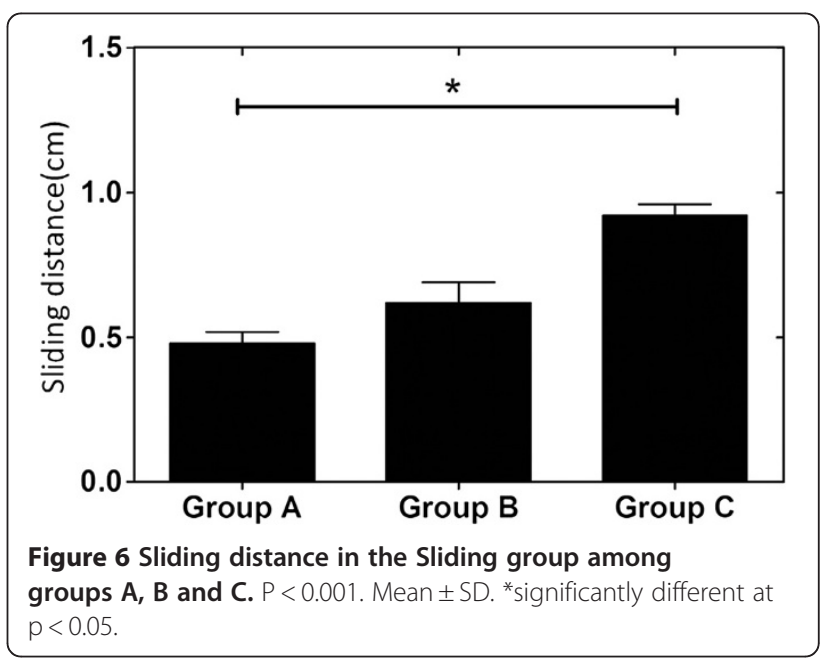


fixation. The healing rate and number of complications are equal to former studies [3,4]. Excessive interfragmental movement may cause bone stiffness and nonunion $[10,27]$. Although this is rare in intertrochanteric fractures fixed by Gamma Nail $[27,28]$ and we didn't observe that problem in our collective. Early operation and early mobilization resulted in a good functional outcome in all patients. In our research, all the patients were instructed to ambulate with partial weight-bearing two weeks after operation in order to get a good rehabilitation result and fracture site impaction. The HHS [29] was used as objective assessment to evaluate the hip function after operation to test whether the lower limb inequality would affect the hip function. To our knowledge, shortening of the lower limb may cause two problems: firstly, the serious limb inequality would lead to a limping gait. Secondly, the adduction strength would decrease with the lower moments. Our research showed no difference of the HHS between each subgroup. We consider both groups to have equivalent results, although shortening of the leg plays little role in the hip function, it is very important to avoid limb length inequality.

The cut-out phenomenon is one of the most common complications of the Gamma Nail. It is often caused by osteoporotic bone and incorrect lag screw positioning [3]. Some biomechanical study even illustrate that impeded sliding of the lag screw may even be one reason of the cut-out phenomenon $[8,22]$. In our study, one patient suffered from cut out because of incorrect lag screw positioning. We could not find any evidence that non-sliding of the lag screw may result in cut out in Gamma Nails. But we still need to investigate more cases to further prove it.

There are still some drawbacks in our research. Firstly, the sample size is not large enough but we suppose that it is sufficient to illustrate our point. Secondly, in addition to our clinical research and we suggest to perform another biomechanical experiment to investigate the differences between the two set-screw fixing formations of the Gamma Nail.

It is evident that the Gamma Nail is a useful and effective system to secure the stable intertrochanteric fractures and equal to its counterpart, the DHS. The hip function one year postoperatively is satisfactory, no matter if the sliding function of the set-screw was used or not. Furthermore, the bone healing rate was similarly high in both groups. Considering the complications of lower limb shortening, the sliding of the lag screw doesn't show any advantages in Gamma nail. As a matter of fact, when using the Gamma Nail, the lower limb discrepancy can be found when the lag screw has not been tightened with the set screw and thus a sliding ability. Moreover, the more comminution the fracture has, the lower limb discrepancy will be observed for A1 and A2 AO-OTA intertrochanteric fractures.

As a result, we can conclude that the sliding distance is minimal in Gamma nails and it is related to the comminuted extent of the intertrochanteric area in A1 and A2 AO-OTA intertrochanteric fractures. For treating these kinds of fractures, the sliding of the lag screw of an Gamma nail does not improve any clinical results and in certain cases, such as highly comminuted A1 and A2 fractures, can therefore even benefit from a locked lag screw by tightening the set-screw.

\section{Competing interest}

The authors confirm that there are no known conflicts of interest associated with this publication and there has been no significant financial support for this work that could have influenced its outcome.

\section{Authors' contributions}

YZ carried out the study design, data collection, analysis, and manuscript writing. MS was involved in the data collection, manuscript revision and editing. CFL and CQZ contributed to the data collection and finalization of the manuscript. All the authors read and approved the final of the manuscript.

\section{Acknowledgements}

The authors acknowledge the contribution of Dr. Severin Meili in the writing of the manuscript.

\section{Author details}

${ }^{1}$ Department of Orthopaedics, Shanghai Sixth People's Hospital, Shanghai Jiaotong University, No.600, YiShan Road, Xuhui District, Shanghai 200233, China. ${ }^{2}$ Fellow of Trauma, Kantonsspital Winterthur, Winterthur, Switzerland.

Received: 24 March 2012 Accepted: 28 August 2012

Published: 1 September 2012

\section{References}

1. Parker MJ, Handoll HH: Gamma and other cephalocondylic intramedullary nails versus extramedullary implants for extracapsular hip fractures in adults. Cochrane Database Syst Rev 2010, 9:CD000093.

2. Platzer $P$, Thalhammer G, Wozasek GE, Vecsei V: Femoral shortening after surgical treatment of trochanteric fractures in nongeriatric patients. J Trauma 2008, 64:982-989.

3. Pascarella R, Cucca G, Maresca A, Commessatti M, Bracci G, Boriani S, Gozzi E: Methods to avoid gamma nail complications. Chir Organi Mov 2008, 91:133-139.

4. Efstathopoulos NE, Nikolaou VS, Lazarettos JT: Intramedullary fixation of intertrochanteric hip fractures: a comparison of two implant designs. Int Orthop 2007, 31:71-76.

5. Schipper IB, Steyerberg EW, Castelein RM, van der Heijden FH, den Hoed PT, Kerver AJ, van Vugt AB: Treatment of unstable trochanteric fractures. Randomised comparison of the gamma nail and the proximal femoral nail. J Bone Joint Surg Br 2004, 86:86-94.

6. Steinberg GG, Desai SS, Kornwitz NA, Sullivan TJ: The intertrochanteric hip fracture A retrospective analysis. Orthopedics 1988, 11:265-273.

7. Rosenblum SF, Zuckerman JD, Kummer FJ, Tam BS: A biomechanical evaluation of the Gamma nail. J Bone Joint Surg Br 1992, 74:352-357.

8. Mahomed N, Harrington I, Kellam J, Maistrelli G, Hearn T, Vroemen J: Biomechanical analysis of the Gamma nail and sliding hip screw. Clin Orthop Relat Res 1994, 304:280-288

9. Yamaji $T$, Ando $K$, Wolf $S$, Augat $P$, Claes $L$ : The effect of micromovement on callus formation. J Orthop Sci 2001, 6:571-575.

10. Epari DR, Taylor WR, Heller MO, Duda GN: Mechanical conditions in the initial phase of bone healing. Clin Biomech (Bristol, Avon) 2006, 21:646-655.

11. Jagodzinski $M$, Krettek $C$ : Effect of mechanical stability on fracture healing-an update. Injury 2007, 38(Suppl 1):S3-10. 
12. Gardner TN, Hardy JR, Evans M, Richardson JB, Kenwright J: The static and dynamic behaviour of tibial fractures due to unlocking external fixators. Clin Biomech (Bristol, Avon) 1996, 11:425-430

13. Haynes RC, Miles AW: Comparative dynamic evaluation of the sliding/ characteristics of the Gamma nail: a biomechanical analysis. Proc Inst Mech Eng H 1997, 211:411-417.

14. Loch DA, Kyle RF, Bechtold JE, Kane M, Anderson K, Sherman RE: Forces required to initiate sliding in second-generation intramedullary nails. J Bone Joint Surg Am 1998, 80:1626-1631.

15. Saudan M, Lubbeke A, Sadowski C, Riand N, Stern R, Hoffmeyer P: Pertrochanteric fractures: is there an advantage to an intramedullary nail?: a randomized, prospective study of 206 patients comparing the dynamic hip screw and proximal femoral nail. J Orthop Trauma 2002, 16:386-393.

16. Schipper IB, Marti RK, van der Werken C: Unstable trochanteric femoral fractures: extramedullary or intramedullary fixation Review of literature. Injury 2004, 35:142-151.

17. Kokoroghiannis C, Aktselis I, Deligeorgis A, Fragkomichalos E, Papadimas D, Pappadas I: Evolving concepts of stability and intramedullary fixation of intertrochanteric fractures-A review. Injury 2011, 46(6):686-693.

18. Gamma 3 Long Nail R2.0 manual (Stryker). http://www.osteosynthesis.stryker. com/medias/pdf/gamma3longnailr2_optech_b0300009d3207.pdf.

19. Lunsjo K, Astrom K, Stigsson L, Sparr G, Hauggaard A, Heyden A, Ceder L, Spanne S: A new radiographic method for evaluating the degree of sliding in devices used in hip-fracture surgery. Acta Radiol 1997, 38:1057-1062

20. Rha JD, Kim YH, Yoon SI, Park TS, Lee MH: Factors affecting sliding of the lag screw in intertrochanteric fractures. Int Orthop 1993, 17:320-324.

21. Leung KS, So WS, Shen WY, Hui PW: Gamma nails and dynamic hip screws for peritrochanteric fractures. A randomised prospective study in elderly patients. J Bone Joint Surg Br 1992, 74:345-351.

22. Kyle RF, Wright TM, Burstein AH: Biomechanical analysis of the sliding characteristics of compression hip screws. J Bone Joint Surg Am 1980, 62:1308-1314.

23. Haidukewych GJ: Intertrochanteric fractures: ten tips to improve results. J Bone Joint Surg Am 2009, 91:712-719.

24. Olsson O, Ceder L, Hauggaard A: Femoral shortening in intertrochanteric fractures A comparison between the Medoff sliding plate and the compression hip screw. J Bone Joint Surg Br 2001, 83:572-578.

25. Wachtl SW, Gautier E, Jakob RP: Low reoperation rate with the Medoff sliding plate: 1 technical failure in 63 trochanteric hip fractures. Acta Orthop Scand 2001, 72:141-145.

26. Davis TR, Sher JL, Horsman A, Simpson M, Porter BB, Checketts RG: Intertrochanteric femoral fractures. Mechanical failure after internal fixation. J Bone Joint Surg Br 1990, 72:26-31.

27. Claes L, Blakytny R, Gockelmann M, Schoen M, Ignatius A, Willie B: Early dynamization by reduced fixation stiffness does not improve fracture healing in a rat femoral osteotomy model. J Orthop Res 2009, 27:22-27.

28. Baumgaertner MR, Curtin SL, Lindskog DM: Intramedullary versus extramedullary fixation for the treatment of intertrochanteric hip fractures. Clin Orthop Relat Res 1998, 348: 87-94.

29. Harris WH: Traumatic arthritis of the hip after dislocation and acetabular fractures: treatment by mold arthroplasty. An end-result study using a new method of result evaluation. J Bone Joint Surg Am 1969, 51:737-755.

\section{Submit your next manuscript to BioMed Central and take full advantage of:}

- Convenient online submission

- Thorough peer review

- No space constraints or color figure charges

- Immediate publication on acceptance

- Inclusion in PubMed, CAS, Scopus and Google Scholar

- Research which is freely available for redistribution

Submit your manuscript at www.biomedcentral.com/submit 